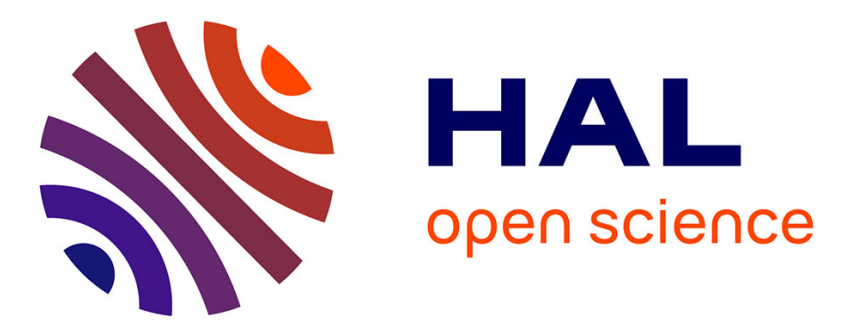

\title{
Live imaging of single platelets at work
}

Karin Sadoul, Laurence Lafanechere, Alexei Grichine

\section{To cite this version:}

Karin Sadoul, Laurence Lafanechere, Alexei Grichine. Live imaging of single platelets at work. Platelets, 2020, 31 (5), pp.551-558. 10.1080/09537104.2019.1708886 . hal-03034501

\section{HAL Id: hal-03034501 \\ https://hal.science/hal-03034501}

Submitted on 5 Jan 2021

HAL is a multi-disciplinary open access archive for the deposit and dissemination of scientific research documents, whether they are published or not. The documents may come from teaching and research institutions in France or abroad, or from public or private research centers.
L'archive ouverte pluridisciplinaire HAL, est destinée au dépôt et à la diffusion de documents scientifiques de niveau recherche, publiés ou non, émanant des établissements d'enseignement et de recherche français ou étrangers, des laboratoires publics ou privés. 


\title{
Live imaging of single platelets at work
}

Karin Sadoul, Laurence Lafanechère and Alexei Grichine

Institute for Advanced Biosciences, University Grenoble Alpes, CNRS UMR 5309, INSERM U1209; Grenoble F-38700, France

Correspondence should be addressed to:

K.S. (e-mail: karin.sadoul@univ-grenoble-alpes.fr) or

A.G. (e-mail: alexei.grichine@univ-grenoble-alpes.fr)

\begin{abstract}
Although live imaging of dynamic processes in platelets is a challenging task, several important observations have been published during the last 20 years. We will discuss the amazing insights that have been achieved, the difficulties that can be encountered as well as some questions still open and the future technical perspectives.
\end{abstract}

\section{Introduction}

In recent years, significant progress has been made in microscopy techniques in terms of speed of acquisition, resolution and sensitivity. This has allowed the improvement of live cell imaging, which in turn has led to the discovery of dynamic processes, which have sometimes been misinterpreted when only static images were analyzed [1]. However, functional imaging of live platelets is still very challenging. These small cellular fragments present some stealthy spatio-temporal features that render molecular mechanisms underlying platelet function particularly difficult to study under the microscope. These features are first of all related to the small size of platelets. With a diameter of $2-5 \mu \mathrm{m}$ in the resting state, their size is only ten times above the resolution limit of standard light microscopy. The second difficulty is related to their physiological role, which is the prevention of life threatening blood loss after vessel injury. To ensure this function platelets are activated in a rather fast process, which is therefore difficult to follow by live cell imaging. Third, platelets are fragile particles, which quickly activate when not carefully manipulated and they have to be used rapidly after their preparation to maintain their physiological properties. Finally, another important complication of platelet fluorescent studies is that platelets originate by fragmentation of the megakaryocyte cytoplasm. Thus, platelets have no nucleus, which precludes their transfection to express fluorescently labeled or optogenetically modified, light-sensitive proteins of interest. To work with platelets expressing tagged proteins, one has therefore to use one of the following approaches. Platelets have to be either purified from genetically modified mice, or produced in vitro by differentiation of megakaryocytes, which have been transfected or virally infected to express an engineered protein; a quite challenging procedure by itself. Other possibilities include the labeling of platelet components, compartments or their microenvironment with molecules coupled to a fluorophore to be able to follow them during platelet activation and/or clot retraction. There are also some new microscopic techniques for label-free platelet imaging. 
For each of these possibilities very elegant studies have been published and some examples are given below by highlighting the cellular processes, which have been discovered.

\section{Labeled platelets isolated from transgenic mice expressing a fluorescent marker}

The use of platelets isolated from GFP-actin (green-fluorescent protein fused to actin) expressing mice has revealed a new type of actin organization, called actin nodules, which form before actin stress fibers appear in spread platelets [2]. The dynamics of actin nodules during platelet spreading on a fibrinogen-coated surface has been nicely quantified by combining Total Internal Reflection Fluorescence (TIRF) and epifluorescence microscopy using platelets purified from mice expressing Lifeact (a 17 aa actin-binding peptide) fused to GFP [3]. Nodules increase in number during the first $20 \mathrm{sec}$ of spreading and have a lifetime of about $22 \mathrm{sec}$. Their size is $\sim 0.22 \mu \mathrm{m}^{2}$ (at appearance and disappearance) but increases to $\sim 0.31 \mu \mathrm{m}^{2}$ at midlife due to both, actin polymerization and a downwards movement of $34.6 \mathrm{~nm}$ towards the substrate. These features are similar to podosome dynamics in megakaryocytes [4] (see also the review about megakaryocytes by XXX et al. in the same issue), albeit much faster and without substrate degradation. The podosome-like protein organization of fixed actin nodules was then described in more detail by higher resolution microscopy (dSTORM, SIM and EM, see also the review about super-resolution microscopy by XXX et al. in the same issue).

By crossing Lifeact-GFP mice with mice knockout for Pdlim7 (an actin binding protein of the PDZ-LIM protein family) it was possible to acquire TIRF-SIM time-lapse videos, which show aberrant reorganization of the actin cytoskeleton in the absence of Pdlim7 expression. This may explain the prothrombotic phenotype of Pdlim7-/- mice and their high postnatal mortality, which is due to systemic venous and arterial thrombosis [5]. The spreading of Lifeact-GFP expressing platelets on a planar lipid bilayer, to which Dylight 594-labeled podoplanin is attached as a ligand, has also been followed by TIRF microscopy. It has been shown that platelets are able to cluster podoplanin, which depends on its receptor CLEC-2 in the platelet plasma membrane and the downstream signaling pathways of Src and Syk kinases [6].

In a recent publication another knock-in mouse has been described in which the ATP receptor P2X1 is fused to the enhanced yellow fluorescent protein (eYFP). The goal was to quantify the lateral mobility of the receptor in the plasma membrane of smooth muscle cells, megakaryocytes and resting platelets using fluorescence recovery after photo bleaching (FRAP). The movement of resting platelets not attached to the glass surface prevented accurate FRAP measurements, but measurements in smooth muscle cells and megakaryocytes has shown that the receptor is highly mobile in the plasma membrane which may prevent desensitization of locally ATP stimulated cell areas [7].

Other transgenic mouse models have been successfully used for in vivo platelet imaging (see review by XXX et al. in the same issue). For instance platelets of the floxed confetti reporter mouse crossed with a megakaryocyte specific Cre mouse (Pf4-Cre mouse) are individually color-labeled due to the stochastic expression of one or several of three different transgenes, cytoplasmic YFP (yellow fluorescent protein), cytoplasmic RFP (red fluorescent protein) and/or plasma membrane CFP (cyan fluorescent protein) [8]. Such platelets, labeled individually by different color combinations, can me easily tracked in a complex 3D environment like a blood clot. Other examples are transgenic 
mice expressing a FRET (Förster resonance energy transfer)-biosensor to follow the activation of kinases like ERK and PAK during in vivo thrombus formation [9]. A FRETbiosensor for kinase activities is typically composed of a phosphorylatable peptide substrate fused to a donor chromophore and combined through a linker sequence with a phosphopeptide-binding domain fused to an acceptor chromophore. The ratiometric FRET quantification using stoichiometric Donor-Acceptor probes is probably the most popular quantification method both in vitro and in vivo. However, it often faces limits related to spectral bleed-through, sequential acquisition, incomplete fluorescent protein maturation and in depth light scattering. Moreover, deciphering signaling networks often requires several biosensors for a simultaneous read-out. Recent technological developments using dark acceptor FRET couples (consisting of a fluorescent Donor and an absorbing but non-emitting or "dark" Acceptor) and fast FLIM imaging allow such multiplexing and an intensity-independent read-out of FRET efficiency [10]. Furthermore, super-resolution optical microscopy such as STED takes benefit of such probes by a resolution increase to nm scale due to non-linear effects [11]. So far, however, no reported applications in the field of platelet research can be found.

\section{Labeled platelets derived in vitro from megakaryocytes engineered to express a fluorescent marker}

Primary mouse megakaryocytes infected with a retroviral vector to express EB3-GFP (a microtubule end-binding protein) have been cultured to generate platelets in vitro. Live imaging of these platelets has allowed to detect growing microtubule tips in the marginal band of resting platelets and to demonstrate that the marginal band is composed of several microtubules [12] and not, as previously thought, of one single microtubule bent to form several circles, thereby constituting the marginal band [13, $14]$.

\section{Staining platelet proteins with fluorescent drugs}

It has long been recognized that resting platelets have a discoid shape due to the peripheral bundle of microtubules. It was also known that their shape becomes more spherical during platelet activation and that this depends on the reorganization of the cytoskeleton. Analysis of fixed, activated platelets has initially led to the conclusion that the marginal band shrinks to a smaller ring due to myosin-induced contraction of the actin-cortex. The smaller microtubule ring, not able to maintain the resting discoid platelet shape, would then lead to the disc-to-sphere transition of activating platelets [15-17]. However, staining of microtubules in resting platelets with the fluorescent microtubule tracker reagent (Oregon GreenTM 488 Taxol, bis-acetate), which passes the plasma membrane, has revealed that the marginal band coils during the platelet activation process. Indeed, the activities of antagonistic microtubule motors of the dynein and kinesin families are in equilibrium in resting platelets. During platelet activation dynein activity overrides kinesin actions and elongates the marginal band. Space constraints then lead to marginal band coiling, which in turn induces the shape change of activating platelets. This has been visualized in 3D by fast confocal line-scan microscopy providing a new mechanistic view of the disc-to-sphere transition of activating platelets [18].

SiR-tubulin and SiR-actin are also probes that can pass the plasma membrane and allow live imaging of the microtubule and actin cytoskeleton. The SiR-probes are based 
on the fluorophore silicon rhodamine ( $\mathrm{SiR}$ ) and the microtubule stabilizing drug docetaxel or the actin stabilizing drug jasplakinolide for SiR-tubulin and SiR-actin, respectively [19]. Using these probes it was shown that the initial spreading process of platelets is followed by a prolonged reorganization of the cytoskeleton [20].

In this context it is also worth mentioning that a detailed study investigated different possibilities of making a fluorescently labeled Lifeact probe capable of crossing the plasma membrane in order to visualize the actin cytoskeleton. In general, these probes work well on fixed cells, but so far they show less satisfactory results in live platelet imaging than imaging platelets expressing Lifeact-GFP [21].

\section{Staining platelet compartments with fluorescent probes}

Using calcein green (a membrane-permeable probe, becoming fluorescent in the cytoplasm of viable cells) stained platelets and Alexa-Fluor 594 coupled fibrinogen it was possible to observe the behavior of individual platelets as well as small platelet aggregates within an in vitro formed fibrin clot. This has shown that platelets repetitively extend filopodia and then retract them once bound to fibrin fibers. This sequential process reveals how platelets manage to generate the degree of clot retraction, which cannot be explained by the simple contraction of the individual platelets but by the compaction and bundling of the fibrin fibers [22].

Staining of the plasma membrane with a fluorescent dye (CellMask DeepRed) has been used to observe platelets on micro-patterned surfaces. It has been shown that platelets extent filopodia to test the composition of the microenvironment in a distance of up to $5 \mu \mathrm{m}$ (corresponding to maximal filopodia extension) and then spread preferentially on areas with a suitable substrate [23].

The same plasma membrane dye has been used to image the spreading process of platelets, which has allowed to distinguish two platelet populations, one spreading via lamellipodia and the other by the extension of several filopodia [24].

The forces developed by individual platelets have been measured by Atomic Force Microscopy (AFM). Platelets stained with CellMask Orange (also staining the plasma membrane) were captured between a glass surface and a cantilever, both of which were coated with fibrinogen. Deflection of the cantilever due to platelet contraction has measured average forces of $29 \mathrm{nN}$ exerted by an individual platelet. Forces were stronger and developed more rapidly at higher micro-environmental stiffness, simulated by the rigidity of the cantilever [25].

In another study, the spreading of CellMask DeepRed stained platelets on an acrylamide gel (containing embedded green fluorescent beads) has allowed the determination of the forces developed by individual platelets using traction force microscopy (TFM). Interestingly, force generation is lagging behind the spreading process and this delay is not influenced by substrate stiffness but correlates with the size of the final spread area [26]. The same team had used TFM before to determine the force field developed by unlabeled platelets spreading on an acrylamide gel with embedded fluorescent beads. A global average force of $34 \mathrm{nN}$ is exerted by an individual platelet after 25 min of spreading. This is in the same order of magnitude as the AFM measurements described above and indicates that platelets represent one of the strongest cell types. Forces are higher in the periphery of the spread platelet, are almost isotropic and point to the center of the spread platelet cell area [27]. 
A combination of different dyes has given insight into the sequence of events leading to the formation of procoagulant platelets within a total population of activating platelets. Fura-red, which shows a bright cytoplasmic fluorescence at low calcium concentrations was used to follow the intracellular calcium rise after agonist addition (resulting in diminished fluorescence). Mitochondria were stained by TMRM (Tetramethylrhodamine methyl ester perchlorate) to record the mitochondrial membrane potential and Rhod-2 was used to monitor the mitochondrial calcium load. The combined use of these markers has shown that activation of platelets by thrombin leads to calcium spikes and eventually to a sustained high calcium concentration. This then causes mitochondrial calcium overload resulting in the successive opening of the mitochondrial permeability transition pores of individual mitochondria within a platelet. Once all the mitochondria within the platelet have lost their membrane potential, platelets become necrotic and expose phosphatidylserine on the outer leaflet of their plasma membrane (visualized by fluorescent annexin- $\mathrm{V}$ binding to the platelet plasma membrane), as a first step towards the procoagulant state [28].

\section{Staining the platelet microenvironment or the platelet surface by fluorescent ligands}

In a recent study the conditions under which platelets are able to migrate in an autonomous fashion have been characterized. Migration is induced by the platelet agonists ADP and thromboxane A2 and is mediated via interactions of $\alpha_{\mathrm{IIb}} \beta_{3}$ integrins with fibrinogen. Platelets start to migrate on a fibrinogen-coated surface in the presence of albumin and calcium, as shown by live imaging of Fura-2 (binding to free intracellular calcium) stained platelets. Platelets adopt a polarized shape due to branched actin formation at the leading edge and myosin IIa dependent trailing edge retraction. While most of the migratory phenotype has been characterized by label free differential interference contrast (DIC) time-lapse microscopy, migration on fluorescently labeled fibrinogen has shown that the high adhesive forces between the integrin receptors and their substrate and the myosin contractile forces lead to removal and collection of the encountered substrate, even when the substrate is composed of entire fibrin fibers. Bacteria can also be collected by migrating platelets and stored until a potential arrival of phagocytes in charge of their clearance [8].

Platelet ballooning and procoagulant spreading has been observed by binding of fluorescently labeled annexin-V to phosphatidylserine, which is exposed on the plasma membrane of a subpopulation of platelets adhering to collagen. The procoagulant nature of these ballooning platelets is characterized by thrombin generation on their plasma membrane as visualized by incubation with a fluorogenic thrombin substrate [29]. In a follow-up study it has been shown that an intracellular calcium rise preceded ballooning as demonstrated by staining of platelets with the calcium sensor Fluo-4 AM. In addition thrombin generation synchronizes ballooning of platelets within an aggregate and the subsequent microvesiculation, which increases the size of the procoagulant surface and thus enhances the development of the hemostatic clot [30].

TIRF videos of platelets stained with Fab fragments directed against the collagen receptor GPVI has allowed to quantify the diffusion of the receptor in the plasma membrane by single molecule tracking [31]. This was possible due to the labeling of the Fab fragments with Atto 647N, a fluorochrom specifically suited for high-resolution microscopy because of its high photostability and strong fluorescence quantum yield. 
This approach has been used to show that the four-transmembrane protein tetraspanin 9 enhances the lateral diffusion of GPVI.

Molecular tension fluorescence microscopy (MTFM) has been used in combination with reflection interference contrast microscopy (RICM) to determine the forces exerted by integrin receptors on the platelet surface after binding to an immobilized extracellular matrix ligand. A glass surface was coated with a fluorescent molecular tension sensor, composed of an RGD peptide (serving as integrin ligand) coupled to a DNA hairpin with a fluorophore at one end and a fluorescence quencher at the other end of the hairpin. When platelets adhere to this surface, a fluorescent signal becomes apparent first in the center and then in the periphery of the spreading platelet due to the binding of integrins to the RGD ligand and the tearing apart of the DNA hairpin liberating the fluorophore [32]. This study also revealed that the timing of phosphatidylserine exposure on the outer leaflet of the plasma membrane (visualized by fluorescent annexin $\mathrm{V}$ binding and corresponding to the procoagulant state of activated platelets) correlates with the loss of the integrin dependent tension signal.

\section{Live imaging of platelets with label free approaches, as an alternative to conventional microscopy}

In order to characterize different aspects of the platelet spreading process a lot of reports have used label free phase-contrast or DIC microscopy. To cite just a few of them, there has been for instance a report in 1979 by Allen et al. describing the shape change of spreading platelets, pseudopodia extensions and even the release of dense granules using DIC video microscopy and images have been compared to scanning electron micrographic pictures [33]. The requirement of the small G-protein Rac for lamellipodia formation during platelet spreading has also been demonstrated using DIC live cell imaging [34]. Real time laser scanning phase-contrast microscopy has been used to describe the importance of phospholipase $\mathrm{C} \gamma 2$ in the signaling cascade initiated by the interaction of $\alpha_{\mathrm{IIb}} \beta_{3}$ integrins with fibrinogen during the spreading process [35]. In recent years several new but related approaches have been used to visualize dynamic processes in platelets without labeling. For instance, scanning ion conductance microscopy (SICM), which is related to atomic force microscopy (AFM), allows the acquisition of platelet spreading processes at high spatial resolution without physical contact of a cantilever with the cell membrane. SICM has allowed to visualize dynamic morphological changes induced by an additional thrombin stimulus on already activated, spread platelets. These reorganizations depend on actin polymerization and on the microtubule motor dynein [36]. In addition to morphological changes, it is also possible to measure by SICM the intrinsic stiffness of different regions of the spread platelets, which has shown that the elastic modulus decreases during thrombin-induced platelet spreading [37]. An evolution of SICM has been the hopping probe mode, which allows spectroscopic and morphological measurements with high precision during the platelet spreading process $[38,39]$.

Besides classical DIC and phase-contrast microscopy, morphological characteristics of live platelets during spreading may also be assessed using dark-field microscopy [40]. This low-cost imaging approach may be very useful for diagnostic screening applications. Another large field scanning approach based on digital inline holography and lens-free imaging has also been successfully used for time-lapse acquisitions of morphological parameters of platelets in a population [41]. 
A promising technique is digital holographic microscopy (DHM), which allows very fast 3D acquisitions and quantification of the volumes of individual platelets or even platelet aggregates [42]. The low light level and the absence of physical contact make it possible to image the inactivated platelets with an axial resolution of up to a few $\mathrm{nm}$.

\section{Concluding remarks}

Through the examples presented above, it is clear that our vision of the dynamic processes underlying platelet function has evolved considerably with the improvement of live imaging techniques. Nevertheless, several questions require further investigation. For instance, after comparing the studies mentioned above, as well as others in the field, it becomes apparent that a part of them describe a different behavior for some platelets within a population while others describe a quite uniform behavior of the total platelet population. Thus, one of the most intriguing, unanswered questions is, whether there are several platelet subpopulations pre-existing in the circulation and if so what is their origin. It is possible that certain assay conditions (for instance platelet washing or not, use of different substrates or agonists at suboptimal concentrations) might reveal different platelet subpopulations in vitro. Alternatively, the differential behavior of platelets within a population could just be a stochastic response of platelets sensing small differences in their microenvironment. The appearance of different platelet subpopulations during hemostasis in vivo is certainly due to the clot architecture being composed of different layers (first arriving platelets at the wound side versus later arriving platelets at the periphery of the forming clot). Obviously, an important parameter, which could influence platelet behavior and generate subpopulations is the different age of platelets within the circulation. The question however remains as to whether, in principle, all platelets in a population are able to perform similarly under appropriate conditions. Some in vitro studies point to a dynamic activation process, which at the final stage could lead to a similar outcome for all platelets $[43,44]$. In contrast, other reports support the hypothesis that platelet subpopulations might be predefined in the circulation [45], eventually due to their origin from different megakaryocyte subpopulations [46-48].

Another open question is whether platelets are able to coordinate their response to divergent stimuli by cellular communication and, if so, whether this is restricted to neighboring platelets in contact with each other or whether messages can also be transmitted by mechanical tension sensing or chemical signaling between distant platelets in a clot. The synchronized ballooning of platelets in a clot supports the idea of a coordinated response [30]. Some further insights to answer this question may come from a microscopic technique called two-point microrheology, which consists in the analyses of correlations between fluctuations of intracellular structures in neighboring cells [49]. Detailed imaging of the collective behavior of platelets and their surroundings under thrombus-like conditions may benefit from new methods based on single plane illumination microscopy (SPIM) also called light-sheet fluorescence microscopy (LSFM) and soSPIM (single objective SPIM) on the subcellular level [50, 51]. These techniques combine fluorescence preserving, single plane excitation, and the high-resolution imaging at video-rate, compatible with single molecule detection and tracking. They can also be applied to cell ensembles like organoids and blood clots. Other interesting approaches for deep-tissue high resolution microscopy are the adaptive optics approaches, which compensate for the specimen induced optical aberrations and can retrieve the diffraction limited resolution (for review see [52]). [53] 
Finally, to mention only one other question among several that could be addressed: which energy production pathways deliver the chemical energy necessary for the various molecular processes converging to the final stage of platelet activation and clot retraction?

Considering that several state-of-the-art imaging techniques are used in the platelet field, we would like to summarize advantages/disadvantages of these microscopic approaches (see table 1) and draw the attention on potential pitfalls that can be encountered.

As mentioned above, platelets are very fragile and can be accidentally activated. For example, the entrance of an inactive platelet into the microscope field of illumination or its contact with an AFM cantilever may activate it due to phototoxic effects of light or mechanical stress, respectively. In the case of living platelets that are stained with fluorophores, such as the taxol-based tubulin tracker [18] or the Fluo-4 $\mathrm{Ca}^{2+}$ probe [30], the phototoxic effects may be potentiated many fold. Thus, extreme care should be taken during experiments by lowering excitation intensities and/or reducing the fluorophore load in order to avoid artificial activation and/or cell damage [54]. Of course, this goes against the need to increase the number of detected photons for a better signal-to-noise ratio and higher temporal and spatial resolution.

Other important aspects to be considered, when staining platelet components with fluorescent drugs, are their labeling specificity and the fact that they may interfere with physiological processes. Indeed, such markers, which are also pharmacological compounds, can affect the process under study. For instance, the taxol-based microtubule probes (tracker and SiR-tubulin) may stabilize the microtubule network and SiR-actin is a jasplakinolide derivative, which induces actin polymerization and stabilization. How these drugs pass the plasma membrane is another critical point to keep in mind. Indeed, for an efficient entry into the cytoplasm, surfactants like pluronic are often added to the drugs in order to destabilize the plasma membrane, which potentially may influence the cellular architecture beneath it $[55,56]$. Nevertheless, alternative methods such as the expression of chimeric fluorescent proteins can also generate artifacts, as discussed for different fluorescent actin binding probes [57].

The capacity of platelets to be easily "triggered on" is accompanied by another microscopy-unfriendly feature that is a very fast activation time-scale. Most activationrelated processes (e.g. disc-to-sphere transition, filopodia extensions, lamellipodia formation, ballooning or procoagulant signaling) are accomplished in just a few minutes; often after a long quiescent phase. Characterization of these events necessitates therefore a large field acquisition method at low light intensity. To this end, the development of techniques, such as dark-field microscopy [40] or lensless wide-field holography [41] is of particular interest. They allow a rapid automatic search for platelets engaged in an activation process and also some quantification, including contact area, fractal dimension or spreading geometry, in a minimally invasive way, albeit with reduced spatial resolution.

Furthermore, to fully characterize the morphological events leading to platelet activation and clotting they need to be followed in three spatial dimensions (4D timelapse). Many studies, however, restrict their observations to imaging of spread platelets on a flat glass surface considering them as pseudo-2D objects. Indeed, the small axial size of the adherent platelet, the absence of a thick nucleus and the limited axial resolution of the optical microscopes make this choice appropriate for the spread phase. Nevertheless, the key events of platelet activation are often related to 3D 
transitions, like disk-to-sphere cytoskeleton reorganization [18] or membrane ballooning [29]. Furthermore, the clot growth itself, through addition of new platelet layers, is by definition a 3D process selected by evolution to create an efficient local positive feed-back loop, amplifying the contraction forces on the vessel walls. Imaging these mechanisms in 3D and over time depends even more on the available photon budget, since it requires high speed and high quality image acquisition at low exposure times.

For all the above listed reasons, the necessary compromise between the spatial resolution, sensitivity and the imaging speed seems to be of particular importance in case of live platelet microscopy. Fortunately, recent spectacular advances in contentaware image restoration [58] look very promising for low-light optical imaging. Thanks to deep-learning training with synthetic or physical data this algorithm allows denoising, recovery of isotropic resolution, 3D projection, and even restoration of subdiffraction structures. Artificial intelligence techniques are also unavoidable in the future for single particle tracking approaches, which currently encounter limitations due to low signal to noise ratios and model biases [59]. Together with the development of parallel imaging modalities for cells and tissues like soSPIM [51] or light-sheet microscopy [50] and correlative optical and non-optical superresolution approaches, a promising future for platelet imaging can be foreseen. 
Table 1:

Currently used classical and advanced microscopy methods in live platelet research including optical and scanning probe modalities. Principal advantages and inconveniences are listed, as well as references for application examples.

\begin{tabular}{|c|c|c|c|}
\hline Method & Refs & $\begin{array}{c}\text { Advantages for Live platelet } \\
\text { imaging }\end{array}$ & $\begin{array}{c}\text { Principal limits and } \\
\text { inconveniences of methods }\end{array}$ \\
\hline $\begin{array}{l}\text { Atomic force } \\
\text { microscopy (AFM) } \\
\text { with or without } \\
\text { gluing a platelet to } \\
\text { the cantilever } \\
\text { Non-photon } \\
\text { imaging, } \\
\text { combinable with } \\
\text { inverted optical } \\
\text { stand }\end{array}$ & $\begin{array}{l}{[25]} \\
{[38]}\end{array}$ & $\begin{array}{l}\text { - Very high spatial resolution } \\
\text { (cantilever dependent) } \\
\text { - Possibility to perform force and } \\
\text { elasticity measurements (related } \\
\text { to the cytoskeleton organization) } \\
\text { between platelets or between a } \\
\text { platelet and a substrate }\end{array}$ & $\begin{array}{l}\text { - Serial acquisition, long image } \\
\text { acquisition time (e.g. } 26 \text { min for } \\
\text { 50x50 } \mu \mathrm{m} \text { ), used only for adherent } \\
\text { platelets } \\
\text { - Artifacts may be present due to } \\
\text { probe sticking to membrane } \\
\text { - Difficulties to glue a platelet to the } \\
\text { cantilever without its activation } \\
\text { - Imaging force may distort 3D shape } \\
\text { of cells, resolution depends on the } \\
\text { elastic modulus (state of the } \\
\text { cytoskeleton) } \\
\text { - Short distance between the cantilever } \\
\text { and the substrate of spread platelets } \\
\text { may impair the results }\end{array}$ \\
\hline $\begin{array}{l}\text { Scanning ion } \\
\text { conductance } \\
\text { microscopy (SICM) } \\
\text { Particularity: } \\
\text { hopping probe } \\
\text { mode } \\
\text { Non-photon } \\
\text { imaging, } \\
\text { combinable with } \\
\text { inverted optical } \\
\text { stand }\end{array}$ & $\begin{array}{l}{[37]} \\
{[38]} \\
{[40]} \\
{[36]}\end{array}$ & $\begin{array}{l}\text { - No direct mechanical contact } \\
\text { between the probe and the } \\
\text { platelet surface - no mechanical } \\
\text { activation of the platelet and no } \\
\text { image deformation due to the } \\
\text { probe 'sticking' to the membrane } \\
\text { - Lateral resolution depends } \\
\text { mainly on the inner diameter of } \\
\text { the glass pipette, often } \\
\text { homemade, typically } 100 \mathrm{~nm} \\
\text { - Useful also to measure } \\
\text { viscoelastic properties }\end{array}$ & $\begin{array}{l}\text { - Serial imaging of one platelet at a } \\
\text { time, relatively long image } \\
\text { acquisition time (6-9 min for 50x50 } \\
\mu \mathrm{m}) \\
\text { - Necessity to manufacture nano- } \\
\text { pipettes } \\
\text { - Essentially used for adherent or } \\
\text { spread platelets, no direct imaging of } \\
\text { internal platelet structures or } \\
\text { organelles possible }\end{array}$ \\
\hline $\begin{array}{l}\text { Confocal } \\
\text { microscopy } \\
\text { modalities: } \\
\text { 1. raster laser } \\
\text { scanning } \\
\text { 2. fast line } \\
\text { scanning } \\
\text { 3. spinning disk }\end{array}$ & $\begin{array}{c}{[18]} \\
{[29]} \\
{[28]} \\
{[22]} \\
{[8]} \\
{[30]} \\
{[9]} \\
{[7]}\end{array}$ & $\begin{array}{l}\text { - High lateral resolution and 3D } \\
\text { optical sectioning } \\
\text { - Parallel acquisition of the field } \\
\text { containing several platelets is } \\
\text { possible } \\
\text { - Possibility to do FRET, FRAP } \\
\text { and photoactivation } \\
\text { 1. Highest confocal spatial } \\
\text { resolution. Moderate imaging } \\
\text { rate of } 1-2 \text { im/s (up to } 30 \text { im/s in } \\
\text { case of using resonant scanner). } \\
\text { Moderate photo-bleaching and } \\
\text { phototoxicity. } \\
\text { 2. Highest temporal resolution due } \\
\text { to parallel (512 pix) excitation } \\
\text { and detection, while keeping a } \\
\text { long pixel dwell time. } \\
\text { Possibility to synchronize the } \\
\text { fast } 2 \mathrm{D} \text { and axial piezo focusing } \\
\text { (up to } 10 \mathrm{~Hz} \text { in small 3D region). }\end{array}$ & $\begin{array}{l}\text { - Diffraction limited point spread } \\
\text { function } \\
\text { - Optical aberrations and light } \\
\text { scattering hamper imaging in thick } \\
\text { clots or in situ } \\
\text { 1. Quite slow acquisition with the } \\
\text { galvanometer raster scanning; } \\
\text { Small pixel dwell time using the } \\
\text { resonant scanner, leading to the bad } \\
\text { S/N ratio and the necessity of the } \\
\text { pixel averaging. } \\
\text { 2. High laser power together with the } \\
\text { rapid image repetition rate lead to } \\
\text { pronounced photobleaching and } \\
\text { activation of platelets even in the } \\
\text { liquid phase. } \\
\text { Anisotropic lateral resolution and } \\
\text { heterogeneous illumination field } \\
\text { are due to excitation optics } \\
\text { geometry. }\end{array}$ \\
\hline
\end{tabular}




\begin{tabular}{|c|c|c|c|}
\hline & & $\begin{array}{l}\text { 3. Least photobleaching thanks to } \\
\text { spatial spread of light and low } \\
\text { intensity excitation. } \\
\text { Fast acquisition (typically }>20 \\
\text { im/s) and good S/N ratio due to } \\
\text { the spinning image averaging. }\end{array}$ & $\begin{array}{l}\text { 3. Less resolved than raster laser } \\
\text { scanning. In case of multicolor } \\
\text { acquisition, the single sized- } \\
\text { pinholes necessitate a } \\
\text { compromised resolution between } \\
\text { different wavelengths. No faster } \\
\text { imaging in smaller regions. }\end{array}$ \\
\hline $\begin{array}{l}\text { Super-resolution } \\
\text { live microscopies: } \\
\text { 1. Single-molecule } \\
\text { localization } \\
\text { microscopy } \\
\text { (SMLM) } \\
\text { 2. Structured } \\
\text { illumination } \\
\text { Microscopy } \\
\text { (SIM) }\end{array}$ & $\begin{array}{l}{[3]} \\
{[5]}\end{array}$ & $\begin{array}{l}\text { - Very high spatial resolution } \\
\text { compared to standard optical } \\
\text { microscopy (x10 and x } 2 \text { for } 1 \text {. } \\
\text { and 2. respectively) } \\
\text { - Derived techniques like single- } \\
\text { molecule tracking photo- } \\
\text { activated localization microscopy } \\
\text { (sptPALM) could be applied to } \\
\text { study molecular dynamics } \\
\text { - Fast SIM would be possible, but } \\
\text { not yet reported for live platelet } \\
\text { imaging }\end{array}$ & $\begin{array}{l}\text { 1. Long acquisition time, essentially } \\
\text { only applied to immobile or fixed } \\
\text { platelets. } \\
\text { Necessitates an evanescent field or } \\
\text { HiLo excitation close to the } \\
\text { glass/platelet interface. } \\
\text { PALM variants need expression of } \\
\text { photoactivatable or photo- } \\
\text { convertible fluorescent proteins. } \\
\text { 2. In case of in-vivo imaging (tissues } \\
\text { or capillaries) structured } \\
\text { illumination suffers from light } \\
\text { scattering by the specimen, limiting } \\
\text { the imaging depth. }\end{array}$ \\
\hline $\begin{array}{l}\text { Dark field (DF) } \\
\text { microscopy } \\
\text { and } \\
\text { Differential } \\
\text { interference } \\
\text { contrast microscopy } \\
\text { (DIC) }\end{array}$ & $\begin{array}{c}{[33]} \\
{[34]} \\
{[6]} \\
{[40]} \\
{[8]}\end{array}$ & $\begin{array}{l}\text { - Classical and robust transmitted } \\
\text { light imaging with low light } \\
\text { exposure. Promising for low-cost } \\
\text { screening with high S/N ratios } \\
\text { - Excellent detection of small } \\
\text { isolated structures (e.g. filopodia } \\
\text { or even platelet microparticles) }\end{array}$ & $\begin{array}{l}\text { - Impossible by DF to distinguish } \\
\text { individual cells or subcellular } \\
\text { structures if applied to platelet } \\
\text { aggregates or thrombi, not applicable } \\
\text { in vivo or to platelets that are spread } \\
\text { above other cells. } \\
\text { - Both methods need sequential } \\
\text { acquisition in case of combination } \\
\text { with epifluorescence. }\end{array}$ \\
\hline $\begin{array}{l}\text { Reflection } \\
\text { interference } \\
\text { contrast microscopy } \\
\text { (RICM) also called } \\
\text { interference } \\
\text { reflectance } \\
\text { microscopy (IRM) } \\
\text { and } \\
\text { Total internal } \\
\text { reflection } \\
\text { fluorescence } \\
\text { microscopy } \\
\text { (TIRFM), also } \\
\text { called evanescent } \\
\text { field microscopy }\end{array}$ & $\begin{array}{c}{[6]} \\
{[3]} \\
{[5]} \\
{[31]} \\
{[32]}\end{array}$ & $\begin{array}{l}\text { - Excellent axial resolution (100- } \\
200 \mathrm{~nm} \text { ) } \\
\text { - Possibility to visualize focal } \\
\text { adhesions, contact area, quantify } \\
\text { the speed of } \\
\text { filopodia/lamellipodia extensions } \\
\text { - Fast acquisition rate in a wide } \\
\text { imaging field. In case of } \\
\text { fluorescent labeling, membrane } \\
\text { or cytoskeleton elements can be } \\
\text { visualized by TIRF and overlaid } \\
\text { with RICM images. RICM may } \\
\text { also be performed in confocal } \\
\text { reflection mode and combined } \\
\text { with confocal fluorescent } \\
\text { imaging in 3D. Very low } \\
\text { photobleaching and } \\
\text { phototoxicity. }\end{array}$ & $\begin{array}{l}\text { - Imaging limited to the contact zone } \\
\text { with the flat glass surface } \\
\text { - No 3D imaging possible with TIRF } \\
\text { (except the variable angle TIRF or } \\
\text { HiLo approaches, not yet reported } \\
\text { for platelets) }\end{array}$ \\
\hline $\begin{array}{l}\text { Digital holographic } \\
\text { microscopy (DHM) } \\
\text { or derived methods } \\
\text { of holotomography } \\
\text { or quantitative } \\
\text { phase imaging }\end{array}$ & [42] & $\begin{array}{l}\text { - Enables the calculation of } \\
\text { heights, dry mass and volumes of } \\
\text { platelets and aggregates without } \\
\text { any labeling using low intensity } \\
\text { coherent light illumination } \\
\text { - The acquisition is fast (ms in case } \\
\text { of DHM), a single hologram } \\
\text { allows digital refocusing through } \\
\text { the whole 3D volume, avoiding } \\
\text { sequential Z-stack acquisitions }\end{array}$ & $\begin{array}{l}\text { - In case of objects thicker than the } \\
\text { wavelength of light the procedure of } \\
\text { the 'phase unwrapping' is necessary } \\
\text { for 3D reconstruction. Uncertainties } \\
\text { may arise, which necessitate ad hoc } \\
\text { hypotheses or 2-color approaches. } \\
\text { - The results are products of distances } \\
\text { and cell refractive index (unknown) } \\
\text { - The holotomography is much slower } \\
\text { and needs specimen holders of } \\
\text { specific geometry, compatible with }\end{array}$ \\
\hline
\end{tabular}




\begin{tabular}{|l|l|l|l|}
\hline & & & the multi-angle illumination. \\
\hline $\begin{array}{l}\text { Lens-less (Lens- } \\
\text { free) imaging }\end{array}$ & {$[41]$} & $\begin{array}{l}\text { - Portable and low cost technique } \\
- \text { Fast and parallel acquisition } \\
- \text { Very wide field of detection } \\
- \text { No labeling necessary }\end{array}$ & $\begin{array}{l}\text { - No fluorescence possible yet } \\
-3 \text { - reconstruction depends on the } \\
\text { chosen model; actually only } \\
\text { spherical cell models work well. } \\
\text { - Many semi-coherent illumination } \\
\text { positions are necessary in case of } \\
\text { complex or entangled objects. }\end{array}$ \\
\hline $\begin{array}{l}\text { Traction force } \\
\text { microscopy (TFM) } \\
\text { or "Fourier } \\
\text { transform traction } \\
\text { cytometry" }\end{array}$ & {$[26]$} & $\begin{array}{l}\text { - Forces exerted on the substrate } \\
\text { can be quantified and mapped in } \\
\text { real time }\end{array}$ & $\begin{array}{l}\text { Platelets challenge traditional TFM- } \\
\text { routines because they are small (2-4 } \\
\mu m \text { ) and strong (up to 10 kPa). Typical } \\
\text { TFM 2D resolution is 1 } \mu \text { m (limited by } \\
\text { the number of detected displacements } \\
\text { per area). Needs specific substrates. }\end{array}$ \\
\hline
\end{tabular}




\section{Acknowledgements}

This work was supported by the Fondation Recherche Médicale (FRM, grant number DEI20151234416) and the University Grenoble Alpes (UGA, grant number AGIR-POLE FRAG15CS08).

\section{Competing financial interests}

The authors declare that they have no competing financial interests.

\section{Author contributions}

All authors participated in writing this review.

\section{References}

[1] Sadoul K. New explanations for old observations: marginal band coiling during platelet activation. J Thromb Haemost 2015;13:333-346.

[2] Calaminus SD, Thomas S, McCarty OJ, Machesky LM, Watson SP. Identification of a novel, actin-rich structure, the actin nodule, in the early stages of platelet spreading. J Thromb Haemost 2008;6:1944-1952. Epub 2008/09/03.

[3] Poulter NS, Pollitt AY, Davies A, Malinova D, Nash GB, Hannon MJ, Pikramenou Z, Rappoport JZ, Hartwig JH, Owen DM, et al. Platelet actin nodules are podosome-like structures dependent on Wiskott-Aldrich syndrome protein and ARP2/3 complex. Nat Commun 2015;6:7254.

[4] Schachtner H, Calaminus SD, Sinclair A, Monypenny J, Blundell MP, Leon C, Holyoake TL, Thrasher AJ, Michie AM, Vukovic M, et al. Megakaryocytes assemble podosomes that degrade matrix and protrude through basement membrane. Blood 2013;121:25422552.

[5] Urban AE, Quick E0, Miller KP, Krcmery J, Simon HG. Pdlim7 Regulates Arf6Dependent Actin Dynamics and Is Required for Platelet-Mediated Thrombosis in Mice. PLoS One 2016;11:e0164042.

[6] Pollitt AY, Poulter NS, Gitz E, Navarro-Nunez L, Wang YJ, Hughes CE, Thomas SG, Nieswandt B, Douglas MR, Owen DM, et al. Syk and Src family kinases regulate C-type lectin receptor 2 (CLEC-2)-mediated clustering of podoplanin and platelet adhesion to lymphatic endothelial cells. J Biol Chem 2014;289:35695-35710.

[7] Mahaut Smith MP, Evans RJ, Vial C. Development of a P2X1-eYFP receptor knock-in mouse to track receptors in real time. Purinergic signalling 2019;15:397-402.

[8] Gaertner F, Ahmad Z, Rosenberger G, Fan S, Nicolai L, Busch B, Yavuz G, Luckner M, Ishikawa-Ankerhold H, Hennel R, et al. Migrating Platelets Are Mechano-scavengers that Collect and Bundle Bacteria. Cell 2017;171:1368-1382 e1323.

[9] Hiratsuka T, Sano T, Kato H, Komatsu N, Imajo M, Kamioka Y, Sumiyama K, Banno F, Miyata T, Matsuda M. Live imaging of extracellular signal-regulated kinase and protein kinase A activities during thrombus formation in mice expressing biosensors based on Forster resonance energy transfer. J Thromb Haemost 2017;15:1487-1499.

[10] Demeautis C, Sipieter F, Roul J, Chapuis C, Padilla-Parra S, Riquet FB, Tramier M. Multiplexing PKA and ERK1\&2 kinases FRET biosensors in living cells using single excitation wavelength dual colour FLIM. Sci Rep 2017;7:41026.

[11] Deng S, Chen J, Gao Z, Fan C, Yan Q, Wang Y. Effects of donor and acceptor's fluorescence lifetimes on the method of applying Forster resonance energy transfer in STED microscopy. J Microsc 2018;269:59-65. 
[12] Patel-Hett S, Richardson JL, Schulze H, Drabek K, Isaac NA, Hoffmeister K, Shivdasani RA, Bulinski JC, Galjart N, Hartwig JH, et al. Visualization of microtubule growth in living platelets reveals a dynamic marginal band with multiple microtubules. Blood 2008;111:4605-4616. Epub 2008/01/31.

[13] Behnke 0, Zelander T. Substructure in negatively stained microtubules of mammalian blood platelets. Exp Cell Res 1966;43:236-239.

[14] Kenney DM, Linck RW. The cystoskeleton of unstimulated blood platelets: structure and composition of the isolated marginal microtubular band. J Cell Sci 1985;78:1-22. Epub 1985/10/01.

[15] Johnson GJ, Leis LA, Krumwiede MD, White JG. The critical role of myosin IIA in platelet internal contraction. J Thromb Haemost 2007;5:1516-1529. Epub 2007/05/10. [16] Severin S, Gaits-Iacovoni F, Allart S, Gratacap MP, Payrastre B. A confocal-based morphometric analysis shows a functional crosstalk between the actin filament system and microtubules in thrombin-stimulated platelets. J Thromb Haemost 2013;11:183186. Epub 2012/11/06.

[17] White JG, Burris SM. Morphometry of platelet internal contraction. Am J Pathol 1984;115:412-417. Epub 1984/06/01.

[18] Diagouraga B, Grichine A, Fertin A, Wang J, Khochbin S, Sadoul K. Motor-driven marginal band coiling promotes cell shape change during platelet activation. J Cell Biol 2014;204:177-185. Epub 2014/01/15.

[19] Lukinavicius G, Reymond L, D'Este E, Masharina A, Gottfert F, Ta H, Guther A, Fournier M, Rizzo S, Waldmann H, et al. Fluorogenic probes for live-cell imaging of the cytoskeleton. Nat Methods 2014;11:731-733.

[20] Paknikar AK, Eltzner B, Koster S. Direct characterization of cytoskeletal reorganization during blood platelet spreading. Prog Biophys Mol Biol 2019;144:166176.

[21] Cardo L, Thomas SG, Mazharian A, Pikramenou Z, Rappoport JZ, Hannon MJ, Watson SP. Accessible Synthetic Probes for Staining Actin inside Platelets and Megakaryocytes by Employing Lifeact Peptide. Chembiochem 2015;16:1680-1688.

[22] Kim OV, Litvinov RI, Alber MS, Weisel JW. Quantitative structural mechanobiology of platelet-driven blood clot contraction. Nat Commun 2017;8:1274.

[23] Kita A, Sakurai Y, Myers DR, Rounsevell R, Huang JN, Seok TJ, Yu K, Wu MC, Fletcher DA, Lam WA. Microenvironmental geometry guides platelet adhesion and spreading: a quantitative analysis at the single cell level. PLoS One 2011;6:e26437. Epub $2011 / 10 / 27$.

[24] Sandmann R, Koster S. Topographic Cues Reveal Two Distinct Spreading Mechanisms in Blood Platelets. Sci Rep 2016;6:22357.

[25] Lam WA, Chaudhuri O, Crow A, Webster KD, Li TD, Kita A, Huang J, Fletcher DA. Mechanics and contraction dynamics of single platelets and implications for clot stiffening. Nat Mater 2011;10:61-66. Epub 2010/12/07.

[26] Hanke J, Probst D, Zemel A, Schwarz US, Koster S. Dynamics of force generation by spreading platelets. Soft Matter 2018;14:6571-6581.

[27] Schwarz Henriques S, Sandmann R, Strate A, Koster S. Force field evolution during human blood platelet activation. J Cell Sci 2012;125:3914-3920. Epub 2012/05/15. [28] Obydennyy SI, Sveshnikova AN, Ataullakhanov FI, Panteleev MA. Dynamics of calcium spiking, mitochondrial collapse and phosphatidylserine exposure in platelet subpopulations during activation. J Thromb Haemost 2016;14:1867-1881. 
[29] Agbani EO, van den Bosch MT, Brown E, Williams CM, Mattheij NJ, Cosemans JM, Collins PW, Heemskerk JW, Hers I, Poole AW. Coordinated Membrane Ballooning and Procoagulant Spreading in Human Platelets. Circulation 2015;132:1414-1424. [30] Agbani EO, Williams CM, Hers I, Poole AW. Membrane Ballooning in Aggregated Platelets is Synchronised and Mediates a Surge in Microvesiculation. Sci Rep 2017;7:2770.

[31] Haining EJ, Matthews AL, Noy PJ, Romanska HM, Harris HJ, Pike J, Morowski M, Gavin RL, Yang J, Milhiet PE, et al. Tetraspanin Tspan9 regulates platelet collagen receptor GPVI lateral diffusion and activation. Platelets 2017;28:629-642.

[32] Zhang Y, Qiu Y, Blanchard AT, Chang Y, Brockman JM, Ma VP, Lam WA, Salaita K. Platelet integrins exhibit anisotropic mechanosensing and harness piconewton forces to mediate platelet aggregation. Proc Natl Acad Sci U S A 2018;115:325-330.

[33] Allen RD, Zacharski LR, Widirstky ST, Rosenstein R, Zaitlin LM, Burgess DR. Transformation and motility of human platelets: details of the shape change and release reaction observed by optical and electron microscopy. J Cell Biol 1979;83:126-142. Epub 1979/10/01.

[34] McCarty OJ, Larson MK, Auger JM, Kalia N, Atkinson BT, Pearce AC, Ruf S, Henderson RB, Tybulewicz VL, Machesky LM, et al. Rac1 is essential for platelet lamellipodia formation and aggregate stability under flow. J Biol Chem 2005;280:3947439484. Epub 2005/10/01.

[35] Wonerow P, Pearce AC, Vaux DJ, Watson SP. A critical role for phospholipase Cgamma2 in alphallbbeta3-mediated platelet spreading. J Biol Chem 2003;278:3752037529. Epub 2003/07/02.

[36] Seifert J, Rheinlaender J, Lang F, Gawaz M, Schaffer TE. Thrombin-induced cytoskeleton dynamics in spread human platelets observed with fast scanning ion conductance microscopy. Sci Rep 2017;7:4810.

[37] Rheinlaender J, Vogel S, Seifert J, Schachtele M, Borst O, Lang F, Gawaz M, Schaffer TE. Imaging the elastic modulus of human platelets during thrombin-induced activation using scanning ion conductance microscopy. Thromb Haemost 2015;113:305-311. [38] Liu X, Li Y, Zhu H, Zhao Z, Zhou Y, Zaske AM, Liu L, Li M, Lu H, Liu W, et al. Use of non-contact hopping probe ion conductance microscopy to investigate dynamic morphology of live platelets. Platelets 2015;26:480-485.

[39] Novak P, Li C, Shevchuk AI, Stepanyan R, Caldwell M, Hughes S, Smart TG, Gorelik J, Ostanin VP, Lab MJ, et al. Nanoscale live-cell imaging using hopping probe ion conductance microscopy. Nat Methods 2009;6:279-281.

[40] Kraus MJ, Seifert J, Strasser EF, Gawaz M, Schaffer TE, Rheinlaender J. Comparative morphology analysis of live blood platelets using scanning ion conductance and robotic dark-field microscopy. Platelets 2016;27:541-546.

[41] Sobieranski AC, Inci F, Tekin HC, Yuksekkaya M, Comunello E, Cobra D, von Wangenheim A, Demirci U. Portable lensless wide-field microscopy imaging platform based on digital inline holography and multi-frame pixel super-resolution. Light Sci Appl $2015 ; 4$.

[42] Boudejltia KZ, Ribeiro de Sousa D, Uzureau P, Yourassowsky C, Perez-Morga D, Courbebaisse G, Chopard B, Dubois F. Quantitative analysis of platelets aggregates in 3D by digital holographic microscopy. Biomed Opt Express 2015;6:3556-3563.

[43] Donati A, Gupta S, Reviakine I. Subpopulations in purified platelets adhering on glass. Biointerphases 2016;11:029811. 
[44] Yakimenko AO, Verholomova FY, Kotova YN, Ataullakhanov FI, Panteleev MA. Identification of different proaggregatory abilities of activated platelet subpopulations. Biophys J 2012;102:2261-2269.

[45] Sodergren AL, Ramstrom S. Platelet subpopulations remain despite strong dual agonist stimulation and can be characterised using a novel six-colour flow cytometry protocol. Sci Rep 2018;8:1441.

[46] Lesyk GM, Jurasz P. Identification of eNOS-based Megakaryocyte Subpopulations and Their Pharmacological Characterization by IFN $\gamma$ and IL-10. The FASEB Journal 2018;32:lb598-lb598.

[47] Radziwon-Balicka A, Lesyk G, Back V, Fong T, Loredo-Calderon EL, Dong B, ElSikhry H, El-Sherbeni AA, El-Kadi A, Ogg S, et al. Differential eNOS-signalling by platelet subpopulations regulates adhesion and aggregation. Cardiovasc Res 2017;113:17191731.

[48] Behnke 0, Forer A. Blood platelet heterogeneity: evidence for two classes of platelets in man and rat. Br J Haematol 1993;84:686-693. Epub 1993/08/01.

[49] Crocker JC, Hoffman BD. Multiple-particle tracking and two-point microrheology in cells. Methods Cell Biol 2007;83:141-178.

[50] Chen BC, Legant WR, Wang K, Shao L, Milkie DE, Davidson MW, Janetopoulos C, Wu XS, Hammer JA, 3rd, Liu Z, et al. Lattice light-sheet microscopy: imaging molecules to embryos at high spatiotemporal resolution. Science 2014;346:1257998.

[51] Galland R, Grenci G, Aravind A, Viasnoff V, Studer V, Sibarita JB. 3D high- and superresolution imaging using single-objective SPIM. Nat Methods 2015;12:641-644.

[52] Li Y, Xia X, Paulus YM. Advances in Retinal Optical Imaging. Photonics 2018;5.

[53] Berdeu A, Laperrousaz B, Bordy T, Mandula O, Morales S, Gidrol X, Picollet-D'hahan

$\mathrm{N}$, Allier C. Lens-free microscopy for 3D + time acquisitions of 3D cell culture. Sci Rep 2018;8:16135.

[54] Waldchen S, Lehmann J, Klein T, van de Linde S, Sauer M. Light-induced cell damage in live-cell super-resolution microscopy. Sci Rep 2015;5:15348.

[55] Batrakova EV, Kabanov AV. Pluronic block copolymers: evolution of drug delivery concept from inert nanocarriers to biological response modifiers. J Control Release 2008;130:98-106. Epub 2008/06/07.

[56] Zhang Z, al-Rubeai M, Thomas CR. Effect of Pluronic F-68 on the mechanical properties of mammalian cells. Enzyme Microb Technol 1992;14:980-983.

[57] Melak M, Plessner M, Grosse R. Actin visualization at a glance. J Cell Sci 2017;130:525-530.

[58] Weigert M, Schmidt U, Boothe T, Muller A, Dibrov A, Jain A, Wilhelm B, Schmidt D, Broaddus $C$, Culley $S$, et al. Content-aware image restoration: pushing the limits of fluorescence microscopy. Nat Methods 2018;15:1090-1097.

[59] Newby JM, Schaefer AM, Lee PT, Forest MG, Lai SK. Convolutional neural networks automate detection for tracking of submicron-scale particles in 2D and 3D. Proc Natl Acad Sci U S A 2018;115:9026-9031. 